\title{
Psychiatry and mental health research in South Africa: national priorities in a low and middle income context
}

\section{J Stein}

Department of Psychiatry and Mental Health, University of Cape Town, Cape Town, South Africa

\begin{abstract}
The recent National Mental Health Summit included discussion of research priorities for South Africa. This paper reviews some of the background literature that is relevant to this key issue. It draws attention to one contested question, the extent to which research in low and middle income countries should address questions about fundamental mechanisms and clinical treatments versus focusing on questions about implementation and systems research? In addressing this question, the paper argues that the boundary between good clinical practice and good academic scholarship is not nearly as distinct as is often assumed (the "research fallacy"); prospective rigorous assessments, retrospective clinical audits, evidence-based medicine, and useful information systems all point to the mutual interdependence of good practice and good scholarship. Finally, some general conclusions that the majority of summit delegates participating in the discussion on research agreed to, are presented.
\end{abstract}

Key words: South Africa; Psychiatry and mental health research; Low and middle-income countries; Research fallacy

Received: 16/09/2012

Accepted: 20/09/2012

doi: http://dx.doi.org/10.4314/ajpsy.v15i6.54

This article is based on a paper presented at the National Mental Health Summit convened by the Department of Health, Republic of South Africa from 12-13 April 2012.

\section{Introduction \\ The recent National Summit on Mental Health included discussion of research priorities for South Africa. This in itself arguably represents a victory for those interested in promoting psychiatry and related research. Nevertheless, given a range of different priorities in psychiatry and mental health, and limited resources particularly in low and middle income countries (LAMICs), the case for research must continue to be made. In this paper some of the literature relevant to this discussion is covered, one particularly important debate is emphasized, a fallacy about research and the mutual interdependence of good clinical practice and good academic scholarship is described, and some conclusions that most summit delegates participating in the discussion on national research priorities agreed with are provided.}

\section{Research in low and middle income countries}

A range of previous publications have addressed the nature of past and on-going psychiatry and mental health research in LAMICs including South Africa, and put forward proposals regarding future work. ${ }^{1-6}$ This section is not intended to provide a systematic or exhaustive review of this body of work, but rather to emphasize a number of key themes that emerge from the existing literature on research activities and priorities in LAMICs, and that are relevant for considering psychiatry and mental health research priorities in the South African context.

The existing literature demonstrates a clear research gap, analogous to the so-called treatment gap in LAMICs. The literature on the treatment gap emphasizes that large numbers of people with psychiatric disorders, particular in LAMICs, do not receive adequate interventions. ${ }^{7-8}$ Work on the research gap, or the difference between the information needed to plan services and that which is available ${ }^{3}$, indicates that $10 \%$ or less of global research resources are spent on diseases that affect more than $90 \%$ of the population (the so called 10/90 gap) ${ }^{9}$, with clear under resourcing of psychiatric and mental health research in LAMICs. ${ }^{10}$

It is also notable that psychiatric and mental health research from LAMIC countries is less likely to be published in high impact psychiatric journals than work from high income countries, with the so-called dissemination gap being in the order of 5/95.11-12 Furthermore, a systematic review found that general medical journals from LAMIC countries were less likely to 
publish articles on psychiatric disorder than were those from high income countries. ${ }^{13}$ Scientific journals therefore have an important role to play in encouraging publication of psychiatric and mental health research in general ${ }^{14}$ and research in LAMIC countries in particular. ${ }^{15-16}$

Despite the research and dissemination gap, there are important opportunities for innovative and relevant psychiatric and mental health research in LAMICs, such as South Africa ${ }^{5,17-20,}$ and such research is indeed occurring. In South Africa, there is evidence of an increase in research on psychiatry and mental health relative to other scientific fields in recent years. ${ }^{21-22}$ Nevertheless, selected priority areas as defined by the South African Medical Research Council are not always addressed. ${ }^{23}$ In the past relatively few publications have involved collaborative research groups and many authors have contributed only one paper ${ }^{24}$, and the future trajectory of research is unclear. ${ }^{21}$ A recent review noted a particular paucity of intervention and economic evaluation studies locally. ${ }^{25}$

Another group of papers has focused on systematic delineation of research priorities in LAMICs. Tomlinson and colleagues polled members of the Lancet Mental Health Group and found that the research questions that scored highest were related to health policy and systems research, where and how to deliver existing cost-effective interventions in a low-resource context, and epidemiological research on child and adolescent psychiatric disorders and substance use disorders. ${ }^{26}$ Sharan and colleagues polled researchers and stakeholders in a wide range of countries and found that epidemiology, health systems and social science ranked highest for type of research, depression/anxiety, substance use disorders and psychoses ranked highest for type of disorder, and children and adolescents and women ranked highest for type of population thought to deserve prioritization. ${ }^{27}$ Key criteria for prioritizing research were burden of disease, social justice, and funding availability. ${ }^{27}$ Khandelwal and colleagues employed a multi-region consultation process, and identified four areas of research priorities;

awareness and advocacy, enhancement of research capacity, training for service delivery, and development of evidence based policy.28

Collins and colleagues used a Delphi panel to identify 25 grand challenges in research that would make an impact on the lives of people living with mental, neurological and substance use (MNS) disorders. These ranged from preclinical questions in etiology (e.g., identifying root causes, risk and protective factors), through preventive and treatment interventions (e.g., advancing prevention, improving treatments), and on to implementation and policy questions (e.g., raising awareness, transforming systems). ${ }^{6}$ Broad themes captured by the challenges included the need for research using a life-course approach, recognition that the suffering caused by MNS disorders extends beyond the patient to families and communities, the point that interventions should be evidence-based, and important relationships between the environment and MNS disorders. ${ }^{6}$

A further set of papers has argued for the importance of health research as a developmental tool, the argument that there is "no health without research". ${ }^{29}$ A related and important strand of psychiatry and mental health research has emphasized the bidirectional links between MNS disorders and poverty. ${ }^{30}$ Certainly, the emergent finding that MNS disorders contribute a significant portion of the burden of disease in LAMICs and in high income countries has been important for motivating for increased research funding in this area. ${ }^{31}$ Work demonstrating that it is cheaper to provide mental health services than not to remains key in arguing for further research on best clinical practice. $^{32-33}$

\section{One Key debate}

It is arguable as to whether the determination that research should focus on children and adolescents, as well as women ${ }^{27}$, is sufficiently narrow to be of use to those involved in resource allocation. On the other hand, overly narrow recommendations run the risk of negatively affecting some areas of psychiatric and mental health research that may be considered important from some perspectives. In this regard, a key debate concerns the extent to which health research in LAMICs should focus on basic versus implementation science, and/or on clinical versus systems research. ${ }^{34}$

On the one hand, given the relative lack of financial and human resources for psychiatric and mental health research in LAMICs, and the availability of a range of efficacious interventions for MNS disorders, it may be argued that research in these contexts should focus primarily on identifying barriers to implementation of existing knowledge, and on systems wide interventions to optimize such implementation. Certainly there is some evidence of structural and attitudinal barriers to psychiatric care in LAMICs such as South Africa ${ }^{35-36}$, as well as data that shed light on how to optimize implementation and scaling-up of evidence-based medical and psychiatric care in such settings s $^{37-43}$, and both literatures deserve further development.

On the other hand, it is also important to acknowledge the limitations in our current knowledge base, and the need for more fundamental research. There is a lack of knowledge not only of the basic neuroscientific and behavioural mechanisms which underpin MNS disorders ${ }^{44}$, but also surprisingly few studies on effective system-wide implementation strategies for improving general health ${ }^{39}$ or mental health in LAMICs. Further, a view that LAMICs should be consumers and implementers of research findings generated by high income countries is clearly not acceptable; local research is needed for local solutions and local development. ${ }^{19,29,45}$ Such work in LAMICs may ultimately also have important implications for high income countries. ${ }^{5,46-47}$ Finally, a view that a non-porous boundary can be drawn between service provision and intervention is questionable, as will be discussed in the next section.

\section{The research fallacy}

It is tempting to draw a line in the sand, so to speak, between clinical services and research processes. In this view, clinicians deliver services for those suffering from psychiatric disorders, while researchers focus on discovering such things as the underlying causes and optimal treatments of these conditions. For several reasons, however, placing clinical and research contributions in diametric opposition is problematic; such a view might be termed the "research fallacy".

Given that randomized controlled trials (RCTs), the gold standard of interventional research, have been undertaken in only limited areas, clinicians are often embarking on a process of trial and error, a clinical experiment with an $\mathrm{n}$ of 1 . Conversely, direct clinical experience provides some of the most important mechanistic insights into the causes and treatments of disorders; the patient with a particular hyperfunction of hypofunction of an endocrine pathway, for example, may provide key knowledge of 
the role that a particular molecule plays in normal function, as well as providing crucial targets for future interventions aimed at reversing the relevant abnormality. Conceptually, then, the boundary between clinical work and the research process is not as distinctive as might be assumed.

The apparent distinction between clinical services and research processes is reinforced by the ethics committee or institutional review board, which insists that investigators (but not everyday clinicians) should submit research protocols, and that research subjects (but not routine patients) sign informed consent. While the regulation of clinical research and the protection of human research subjects are clearly legitimate aims, such distinctions arguably also lead to a crucial under emphasis of the extent to which standard clinical services also entail a process of experimentation. ${ }^{48}$ While some conceptualize participation in clinical research as "experimental", or alternatively as a way to access high quality clinicians and treatment, current evidence indicates that outcomes of patients who participate in RCTs is comparable to that of similar patients receiving similar treatments outside of RCTs. ${ }^{49}$

Notably, processes such as clinical audits emphasize the fuzziness of the line between services and research. Clinical audit is partly a quality improvement intervention which provides clinicians with a means of impacting positively on treatment outcomes. ${ }^{50}$ On the other hand, clinical audit can be conceptualized as essentially a retrospective investigation of the effects of treatment. Indeed from an ethics committee or institutional review board perspective, protocols for such work ought to be formally submitted for assessment. The use of structured diagnostic instruments, standardized symptom severity scales, and computerized information systems similarly can be viewed either as enhancing routine practice, or making such care sufficiently rigorous that it can be considered as in effect comprising clinical research.

Evidence-based medicine is often criticized for relying overly on a narrow research base. However, such criticism entails a deep misunderstanding of the nature of evidencebased medicine. Evidence-based medicine in fact relies not only on the existing research base, but also on clinical expertise and patient values. ${ }^{51}$ Thus, the practice of evidence-based medicine effectively underlines the fuzzy line between good practice and good scholarship, and their mutual interdependence. Along these lines, it may well be argued that just as there is an ethical imperative to scale up services in LAMICs ${ }^{52}$, so there is a moral obligation to undertake research on key clinical issues. ${ }^{53}$

\section{Proposals for the future}

Delegates to the national summit on mental health discussed these kinds of conceptual issues. There was no formal prioritysetting process, a potentially crucial limitation. ${ }^{54}$ At the same time, a large number of stakeholders attended the summit and gave inputs from previously held provincial summits, and the majority of those participating in the research session agreed to a number of proposals that are consistent with a wide range of existing literature on psychiatric and mental health research priorities in LAMICs:

1. South Africa needs a broad range of psychiatric and mental health research, spanning the range from basic neuroscience and behavioural science through to clinical research and on to public health research. Currently there are major opportunities for advancing basic and clinical neuroscience ${ }^{6,19}$, and it is important for developing countries to also have expertise in this area. Good clinical practice and clinical research are intimately intertwined, and this intersection should be encouraged, in the full range of mental health professionals and consumer organizations. ${ }^{55-56}$ Regular epidemiological surveys of the prevalence of MNS disorders are important given the public health importance of these conditions ${ }^{57}$, and research on stigma and mental health literacy is key. ${ }^{58-59}$

2. It is particularly important to develop clinical and health system interventions that are suitable for a resource limited context. ${ }^{60-61,42}$ These may well include culturally appropriate task-shifting or task-sharing and stepped care interventions. It is appropriate to focus on areas where intervention is likely to have maximal benefit in terms of effectiveness, cost-efficiency, and potential for being scaled up; for example, integrated primary care or community worker interventions that reduce depression or substance consumption pre- and postpartum ${ }^{62-63}$, that maximize adherence to effective treatments for chronic conditions including HIV/AIDS ${ }^{64-66}$, or that promote stigma reduction and mental health literacy in other high risk group. ${ }^{58-59,67}$

3. In moving forward, both research "relevance" and "excellence" should be encouraged. ${ }^{68}$ There is "no health without mental health" 69 , and it is crucially important that in research funding globally there is parity of resources for research on psychiatry and mental health, matching the growing contribution of psychiatric disorders to the global burden of disease. ${ }^{70}$ Similarly, there is a need for improved capacity development, developing career paths, and institutional support for basic scientists and clinicianscientists, including those working in sub-specialties. ${ }^{71-72}$ Structures need to be established and developed for optimizing research governance, collaboration between researchers, policy-makers and other stakeholders, and an emphasis on social justice and human rights in order to effect goals. ${ }^{73-74}$ Notably, a research perspective emphasizes the importance of evidence-based clinical practice ${ }^{51}$, and of evidence-based policy making in both general medicine, and in psychiatry and mental health. ${ }^{75}$

\section{Conclusion}

The national mental health summit was important in many ways, not the least being the opportunity it created for discussing research priorities in psychiatry and mental health in South Africa. Indeed, arguably there is no greater single priority in psychiatry and mental health research locally, than for research to be a key part of the on-going discussion on how to improve current and future clinical services, and for both health interventions and policies to be evidence-based. While in resource-constrained settings there is understandably strong interest in implementation science and health systems, it is also important to emphasize how fundamental research and clinical interventions may contribute to local solutions and local development. All too often research is viewed as something separate from practice, perhaps to be undertaken by a privileged few in their ivory towers. In this article the argument has been made that such a perspective constitutes a "research fallacy" and that research should be part and parcel of the clinical coalface. There is a need for a broad-based research agenda that ranges from basic science, through clinical investigations, and on to public health research. It is particularly 
important to develop clinical and health system interventions that are suitable for a resource limited context. Successful implementation of such an agenda will require appropriate governance and resourcing.

\section{Acknowledgements}

Prof Stein is supported by the Medical Research Council of South Africa. Thanks to Profs Crick Lund, Soraya Seedat, and Mark Tomlinson for reviewing a draft of this manuscript.

\section{References}

1. Sartorius N. Scientific work in third world countries. Acta Psychiatrica Scandinavica 1998; 98 345-7.

2. Alem A, Kebede D. Conducting Psychiatric research in the developing world: challenges and rewards. British Journal of Psychiatry 2003; 182: 185-7.

3. Saraceno B, Saxena S. Bridging the mental health research gap in lowand middle-income countries. Acta Psychiatr Scand 2004; 1 : 1-3.

4. Maj M.Psychiatric research in low- and middle-income countries: the need for concrete action. ActaPsychiatricaScandinavica 2005; 111: 329-30.

5. Stein DJ, Seedat S. From research methods to clinical practice in psychiatry: challenges and opportunities in the developing world. International Review of Psychiatry 2007; 19: 573-81.

6. Collins PY, Patel V, Joestl SS, March D, Insel TR, Daar AS, et al. Grand challenges in global mental health.Nature 2001;475: 27-30.

7. Kohn R, Saxena S, Levav I, Saraceno B.The Treatment Gap in Mental Health Care.Bull WHO 2004; 82: 858-866.

8. Demyttenaere K, Bruffaerts R, Posada-Villa J, Gasquet I, Kovess V, Lepine $J$, et al. .Prevalence, severity, and unmet need for treatment of mental disorders in the World Health Organization World Mental Health Surveys.JAMA2004; 291: 2581-2590.

9. Global Forum for Health Research. Some network in research priority areas. In: Davey S, editor. The 10/90 report on health research: 2003-2004. Geneva: Global Forum for Health Research; 2004. Available from: http://www.globalforumhealth.org.

10. Razzouk D, Sharan P, Gallo C, Gureje O, Lamberte EE, de Jesus Mari J, et al. . Scarcity and inequity of mental health research resources in low-andmiddle income countries: a global survey. Health Policy 2010; 94: 211-20.

11. Patel V, Sumathipala A.International representation in psychiatric literature: survey of six leading journals. British Journal of Psychiatry2001; 178: 406-9.

12. de Jesus Mari J, Patel V, Kieling C, Anders M, Jakovljevi M, Lam LC, et al. . The 5/95 Gap on the dissemination of mental health research: The World Psychiatric Association (WPA) task force report on project with editors of low and middle income (LAMI) countries. African Journal of Psychiatry2009; 12: 33-9.

13. Ipser JC, Stein DJ.Little mental disorder research in general medical journals in low - and middle-income countries.South African Medical Journal 2007; 97: 110-111.

14. Griffiths KM, Banfield M, Leach L. Mental health research in The Lancet: a case study. Journal of Mental Health 2010; 19: 17-25.

15. Editors of Scientific Journals Publishing Mental Health Research. Galvanizing Mental Health research in low- and middle-income countries: the role of scientific journals. American Journal of Orthopsychiatry 2004; 74: 389-92.

16. Saxena S, Paraje G, Sharan P, Karam G, Sadana R. The 10/90 divide in mental health research: trends over a 10-year period. British Journal of Psychiatry 2006; 188: 81-2.

17. Stein DJ, Emsley RA. Psychiatric research in the new South Africa. S Afr J Psychiatry 1995;85:1365-1366.
18. Seedat S, Emsley RA, Stein DJ. Land of promise: challenges and opportunities for research in South Africa. Molecular Psychiatry 2004; 9 : 891-892

19. Stein DJ, Daniels W, Emsley R, Harvey B, Blackburn J, Carey P, et al. A brain-behaviour initiative for South Africa: the time is right. Metabolic brain disease 2006; 21: 279-84.

20. Lund C, Stein DJ, Corrigall J, Bradshaw D, Schneider M, Flisher AJ. Mental health is integral to public health: a call to scale up evidence-based services and develop mental health research. South African Medical Journal 2008; 98: 444-446.

21. Stein D, Szabo C. Psychiatry research in South Africa reason for cautious celebration? African Journal of Psychiatry 201 1; 14 :86.

22. Pouris A. Science in South Africa: The Dawn of a Renaissance? South African Journal of Science 2012; 108: 66-71.

23. Flisher A, Parry C, Stein J D. To what extent does South African mental health and substance abuse research address priority issues $S$ Afr Med J 2000; 90: 378-380.

24. Fourie A J, Flisher J A, Emsley A R, Stein J D. Psychiatric research in South Africa: A systematic review of Medline publications. Curationis 2001;24:9-11.

25. Petersen I, Lund C. Mental health service delivery in South Africa from 2000 to 2010: one step forward, one step back. South African Medical Journal 2011; 101: 751-7.

26. Tomlinson M, Rudan I, Saxena S, Swartz L, Tsai AC, Patel V. Setting priorities for global mental health research. Bulletin of the World Health Organization 2009; 87: 438-46.

27. Sharan P, Gallo C, Gureje O, Lamberte E, Mari JJ, Mazzotti G, et al. Mental health research priorities in low- and middle-income countries of Africa, Asia, Latin America and the Caribbean. British Journal of Psychiatry 2009; 195: 354-63.

28. Khandelwal S, Avodé G, Baingana F, Conde B, Cruz M, Deva P, et al. Mental and neurological health research priorities setting in developing countries. Social Psychiatry and Psychiatric Epidemiology 2010; 45: 487-95.

29. Ij.sselmuiden C, Marais DL, Becerra-Posada F, Ghannem H. Africa's neglected area of human resources for health research - the way forward. South African Medical Journal 2012; 102: 228-33.

30. Lund C, De Silva M, Plagerson S, Cooper S, Chisholm D, Das J, et al. Poverty and mental disorders: breaking the cycle in low-income and middle-income countries.Lancet 201 1; 378: 1502-14.

31. Lopez AD, Mathers CD, Ezzati M, Jamison DT, Murray CJ. Global and regional burden of disease and risk factors, 2001: systematic analysis of population health data Lancet2006; 367:1747-1757.

32. Chisholm D, Sanderson K, Ayuso-Mateos L J, Saxena S. Reducing the global burden of depression: Population-level analysis of intervention cost-effectiveness in 14 world regions. Br J Psychiatry 2004; 184:393-403.

33. Lund C, Myer L, Stein D, Williams D, Flisher A (n.d.).Mental ill-health and lost income among adult South Africans.Social Psychiatry and Psychiatric Epidemiology, in press.

34. Schneider M. The Setting of Health Research Priorities in South Africa Cape Town: Medical Research Council; 2001.

35. Seedat S, Stein DJ, Berk M, Wilson Z. Barriers to treatment among members of a mental health advocacy group in South Africa. Social Psychiatry and Psychiatric Epidemiology 2002; 37: 483-487.

36. Bruwer B, Sorsdahl K, Harrison J, Stein DJ, Williams D, Seedat S. Barriers to mental health care and predictors of treatment dropout in the South African Stress and Health Study. Psychiatric Services 2001; 62: 774-81.

37. Haines A. Bridging the implementation gap between knowledge and action for health. Bulletin of the World Health; 2004; 82:724-3.

38. Chisholm D, Flisher AJ, Lund C, Patel V, Saxena S, Thornicroft G, et al. Scale up services for Mental Disorders: a call for action. Lancet 2007; 370: $1241-52$. 
39. Lewin S, Lavis JN, Oxman AD, Bastías G, Chopra M, Ciapponi A, et al. Supporting the delivery of cost-effective interventions in primary healthcare systems in low-income and middle-income countries: an overview of systematic reviews. Lancet 2008; 372: 928-39.

40. Guyatt GH, Oxman AD, Kunz R, Jaeschke R, Helfand M, Liberati A, et al. Incorporating considerations of resources use into grading recommendations. BMJ 2008; 336: 1170-3.

41. Rosenbaum SE, Glenton C, Wiysonge CS, Abalos E, Mignini L, Young T, et al. Evidence summaries tailored to health policy-makers in low- and middle-income countries. Bulletin of the World Health Organization2001; 89: 54-61.

42. Petersen I, Lund C, Stein DJ. Optimizing Mental Health services in lowincome and middle-income countries. Current Opinion in Psychiatry 2001; 24: 318-23.

43. Murthy L, Shepperd S, Clarke MJ, Garner SE, Lavis JN, Perrier L, et al.Interventions to improve the use of systematic reviews in decisionmaking by health system managers, policy makers and clinicians. Cochrane Database of Systematic Reviews 2012; 9: CD009401.

44. Insel R T, Quirion R. Psychiatry as a Clinical Neuroscience discipline. JAMA 2005; 294; :2221-4.

45. Stein DJ, Emsley RA, Oosthuizen P, Berk M. The importance of industry sponsored clinical trials in South Africa. Journal of Depression and Anxiety 2000; 3:1

46. McKenzie K, Patel V, Araya R. Learning from low income countries: Mental Health. BMJ 2004; 329: 1138-40

47. Patel V, Chowdhary N, Rahman A, Verdeli H. Improving access to psychological treatments: lessons from developing countries. Behaviour Research and Therapy 2011; 49: 523-8.

48. Chalmers I, Lindley R.Double standards on informed consent to treatment. In: Doyal L, Tobias JS (eds). Informed Consent: Respecting Patients' Rights in Research, Teaching and Practice. London: BMJ Publications, 2000, pp.266-75.

49. Vist GE, Bryant D, Somerville L, Birminghem T, Oxman AD. Outcomes of patients who participate in randomized controlled trials compared to similar patients receiving similar interventions who do not participate. Cochrane Database of Systematic Reviews 2008; 16:MR000009.

50. Ivers N, Jamtvedt G, Flottorp S, Young JM, Odgaard-Jensen J, French SD, et al. Audit and feedback: effects on professional practice and healthcare outcomes. Cochrane Database of Systematic Reviews 2012;6:CD000259.

51. Sackett L D, Rosenberg $M, C W$, Muir Gray A J, Richards $S W$. Evidencebased medicine: What it is and what it isn't. BMJ1 996;312:71-2

52. Patel V, Bloch S. The ethical imperative to scale up health care services for people with severe mental disorders in low and middle income countries. Postgraduate Medical Journal 2009; 85: 509-13.

53. Stein DJ.Philosophy of psychopharmacology.Cambridge University Press; 2008

54. Tomlinson M, Chopra M, Hoosain N, Rudan I. A review of selected research priority setting processes at national level in low and middle income countries: towards fair and legitimate priority setting. Health Research Policy and Systems 201 1; 9: 19.

55. Stein DJ, Wessels C, Zungu-Dirwayi N, Berk M, Wilson Z. Value and effectiveness of consumer advocacy groups: A survey of the anxiety disorders support group in South Africa. Depression and Anxiety 2001;13:105-107.

56. Barrett T, Boeck R, Fusco C, Ghebrehiwet T, Yan J, Saxena S. Nurses are the key to improving mental health services in low- and middle-income countries. International Nursing Review 2009; 56: 138-41.

57. Stein DJ, Williams DR, Kessler RC. The South African Stress and Health (SASH) study: a scientific base for mental health policy. South African Medical Journal 2009; 99: 337.
58. Ganasen KA, Parker S, Hugo CJ, Stein DJ, Emsley RA, Seedat S. Mental health literacy: Focus on developing countries. African Journal of Psychiatry 2008; 11:23-8.

59. Corrigan PW, Morris SB, Michaels PJ, Rafacz JD, Rüsch N. Challenging the Public Stigma of Mental Illness: A Meta-Analysis of Outcome Studies. Psychiatric Services 2012, in press.

60. Sorsdahl K, Stein DJ, Flisher AJ.Traditional healer attitudes and beliefs regarding referral of the Mentally Ill to Western doctors in South Africa.Transcultural Psychiatry 2010; 47: 591-609.

61. Van't Hof E, Cuijpers P, Waheed W, Stein DJ. Psychological treatments for depression and anxiety disorders in low- and middle- income countries: a meta-analysis. African Journal of Psychiatry 201 1; 14: 200-7.

62. Cooper PJ, Tomlinson M, Swartz L, Landman M, Molteno C, Stein A, et al. Improving quality of mother-infant relationship and infant attachment in socioeconomically deprived community in South Africa: randomised controlled trial. BMJ 2009; 338:974.

63. Rotheram-Borus MJ, le Roux IM, Tomlinson M, Mbewu N, Comulada WS, le Roux K, et al. Philani Plus (+): a Mentor Mother community health worker home visiting program to improve maternal and infants' outcomes. Prevention Science 2011; 12: 372-88.

64. Collins PY, Holman AR, Freeman MC, Patel V. What is the relevance of mental health to HIVIAIDS care and treatment programs in developing countries? A systematic review.AIDS 2006; 20: 1571-1582.

65. Joska JA, Hoare J, Stein DJ, Flisher AJ. The neurobiology of HIV dementia: implications for practice in South Africa. African Journal of Psychiatry 2011; 14: 17-22.

66. Woltmann E, Grogan-Kaylor A, Perron B, Georges H, Kilbourne AM, Bauer MS. Comparative effectiveness of collaborative chronic care models for mental health conditions across primary, specialty, and behavioral health care settings: systematic review and meta-analysis. American Journal of Psychiatry 2012; 169: 790-804.

67. Thornicroft G, Alem A, Antunes Dos Santos R, Barley E, Drake RE Gregorio G, et al. WPA guidance on steps, obstacles and mistakes to avoid in the implementation of community mental health care. World Psychiatry 2010; 9: 67-77.

68. Tol WA, Patel V, Tomlinson M, Baingana F, Galappatti A, Silove D, et al. Relevance or excellence? Setting research priorities for mental health and psychosocial support in humanitarian settings. Harvard Review of Psychiatry2012; 20: 25-36.

69. World Health Organization (2001): The World Health Report 2001: Mental Health: New Understanding, New Hope. Geneva: World Health Organization 2001

70. Rochon PA, Mashari A, Cohen A, Misra A, Laxer D, Streiner DL, et al. Relation between randomized controlled trials published in leading general medical journals and the global burden of disease. CMAJ 2004; 170: 1673-7.

71. Stein DJ, Betancourt OA, Emsley RA, Jeenah Y, Mkize D, Pretorius J, et al. Sub-specialties in psychiatry: towards parity in mental health training and services. South African Medical Journal 2009; 99: 38-9.

72. Stein DJ, Szabo CP, Moussaoui D, Gureje O.Psychiatric subspecialization in Africa - introduction to a series. African Journal of Psychiatry2010; 13: 157-9.

73. Yasamy MT, Maulik PK, Tomlinson M, Lund C, Van Ommeren M, Saxena $S$. Responsible governance for mental health research in low resource countriesPLoS Medicine 2001; 8: el 1001126.

74. Tomlinson $M$, Lund $C$. Why does mental health not get the attention it deserves? An application of the Shiffman and Smith framework 2012;PLoS medicine 9: el001178.

75. Oxman AD, Lavis JN, Lewin S, Fretheim A. SUPPORT Tools for evidenceinformed health Policymaking (STP) 1: What is evidence-informed policymaking? Health Research Policy and Systems 2009; 7S1: 1. 